\title{
Problems in Expressing Arabic Language of Indonesian Students at Khartoum International Institute for Arabic Language
}

\author{
Mochammad Firdaus
}

\author{
Universitas Muhammadiyah Malang, Indonesia \\ e-mail : fery.elfirdausy@gmail.com
}

This study was started with disclosure of issues faced by Indonesian students in Khartoum International Institute of Arabic Language. The main objective of this research revealed the ta'bir problem afflicting Indonesian students in learning classical Arabic, identifying the causes and knowing the impact of these problems in educational situations. To achieve the objective of this study, the method used by the researcher is descriptive analytical method. The results of this research are:

1) The ways which Indonesian students learned Arabic language in their institution have become instruments in improving Arabic language, 2) The impacts of the Indonesian

Abstract dialects made difficulties for students in forming the Arabic dialect, 3) Environment in which treated the students outside the University affecting their ability in speaking classical Arabic, and 4) Weakness in disclosure affected students' academic achievement. Then the researcher suggested solutions to solve those problems such as: 1) To help the students to develop their process in traditional Arabic, it is needed to the students to take the benefits from any means, as teacher teaches them by reading newspaper, magazine and scientific journal which gave them increase the outcome of their linguistics ability, 2) The commitment from the lectures of all subjects to speak in well-structured Arabic and avoid using slank is needed.

Keyword

Khartoum International Institute of Arabic Language; Student of Indonesia; Ta'bir Problems

$$
\begin{aligned}
& \text { بدأت هذه الدراسـة بالكشف عن القضايا التي يواجهها الطلاب الإندونيسيين } \\
& \text { بمعهد الخرطوم الدولي للغة العربية. هدفت الدراسة إلى كشف مشكلات }
\end{aligned}
$$

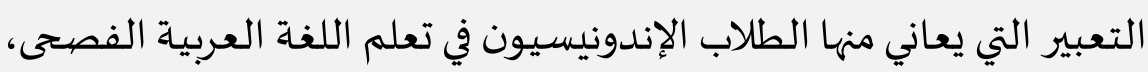

$$
\begin{aligned}
& \text { وتحديد أسباب المشكلات ومعرفتها في العملية التعليمية. لتحقيق الهدف من }
\end{aligned}
$$

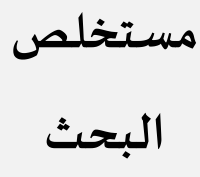

Please cite this article as Mochammad Firdaus. (2019). Problems in Expressing Arabic Language of Indonesian Students at Khartoum International Institute for Arabic Language. Izdihār : Journal of Arabic Language Teaching, Linguistics, and Literature, 2(1), 35-52. DOI: 
هذه الدراسة، الطريقة التي يستخدمها الباحث هي الطريقة التحليلية الوصفياة. وأما نتائج هذا البحث فهي: () الطرق التي تعلم بها الطلاب الإندونيسيون اللغة العربية في مؤسستهم أصبحت أدوات في تحسين اللغة

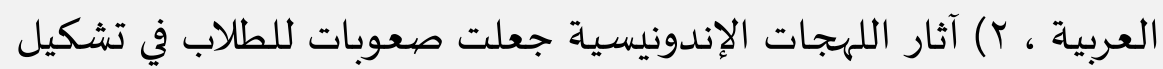
لهجة العربية ، ب) البيئة التي عالجت الطلاب خارج الجامعة مما أثر على

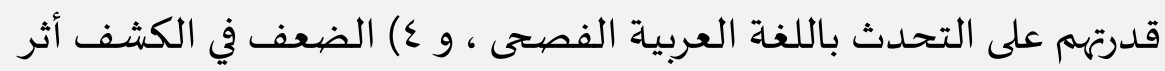

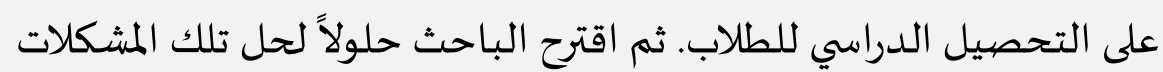
وهي: () لمساعدة الطلاب على تطوير عمليتهم باللغة العربية التقليدية، يحتاج الطلاب إلى الاستفادة من أي وسيلة، حيث يعلمهه المعلم عن طريق قراءة الصحف والمجلات العلمية التي منحتهم إلى زيادة نتائج قدرتهم اللغوية، r) الالتزام من محاضرات جميع المواد للتحدث باللغة العربية جيدة التنظيم وتجنب استخدام اللغة العامية.

معهد الخرطوم الدولي للغة العربية؛ الطلاب الإندونيسيون؛ مشكلات كلمات التعبير أسـاسية

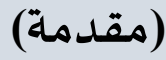

يعـد العقل من أهـم مـا يمتـاز بـه الإنسـان عـن بـاقي الكائنـات الحيـة، تتمثل تلك في قـدرات الفـرد العقليـة على اسـتخدام اللغـة بألفاظهـا وتراكيبها.وتعـد اللغــة مـن أهـم الظـواهر الاجتماعيـة الناتجـة عن التطور البشـري إذ تلعب دوراً وظيفياً مهماً في حياة الفرد والمجتمع. فهي وسيلة اتصـال الفرد بغيره، وعن طريق الاتصيال يـرك الفرد حاجاتـه ومتطلباته، وهي وسيلته للتعبيز عـن أفكاره وعواطفه وانفعالاته. ولغة كل أمة جزء لا يتجزأ من شخصيتها وحضيارتها وموروثها التاريخي والثقافي. ولأهمية اللغة قام العديد من الباحثين بدراسـة ألفاظها ومفرداتها وتراكيبها وكانت مدار الاهتمام إذ إنها وسيلة للتفكير والتفاهم. واللغــة العربيـة كإحسدى لغـات العـالم تمتــاز بتاريخهـا الطويـل المتصـل، و ثروتهـا الفكريـة والأدبية تقوم بالحفاظ على بقاءها و ازدهارها. فمن أجل ذلك قامت المدارس و المراكز الإسلامية فى جميع البلاد العربية بالاهتمام على نشرهاو تعليمها ووضع البرامج لتنميتها. 
وطرق تعليم اللغـة التى ولدتها الاتجاهـات الحديثة تميل إلى تعليم اللغـة من خلال مفهوم

المهارات، وهي: التحـدث، الاستماع، القـراءة، و الكتابـة يقـول عمر الصيديق أن الوظيفـة الأسـاسيـة للغة هي الاتصال(عمر الصديق, ^. . ؟ : م). فأصبح الناس محتاجين إلى تلك المهارات اللغوية حتى يكونوا قادرين على الاتصال أو التواصل مع الآخرين بفعالية فى مواقف و مجالات شتى. والتعبير فرع من فروع اللفـة بل هو أسـاس كل الفروع وهو وسيلة الإنسـان الأولى للإفصـاح

عما يدور في خلده من أحاسيس ومدركات للا تصال بالمجتمع الذي يعيش فيه ويتفاعل معه. و التعبير الجيد هو أسس التفوق الدراسي في المجال اللغوي و مجالات الحياة المدرسية و الموضيوعات الدراسية جميعها، لأن من يسيطر على قدرات التعبير و مهارتاه يستطيع السيطرة على الكلمة المناسبة و العبارة الهادفة و يتفوق فى الحياة العملية. فغاية التعبير أن يجعل الطالب قادرا

$$
\text { على اختيار الأسلوب السليم و حسن الترتيب شفهياو تحريريا. }
$$

إن مشـكلة ضـعف الطلبـة في التعبير ليسـت حديثـة العهـد بـل إنها ذات عمق تاريخي، فقد

أشـار ابن خلدون الى هذه المشكلة معللا أسبابها بأن الضعف في التعبير عائد الى غياب المناخ الملائم الذي يسهم في إيجاد ميدان تطبيقي لما يتعلمه الطالب من قدرة على التعبير (العزاوي، 1917 (10). هناك العديد من الدراسـات التي جعلت من ضـعف الطلبة في التعبير موضيوعها الرئيس وسعت إلى تشخيص أسـباب الضـعف التي تعـددت بتعـدد هـذه الدراسـات. ولاحظظ الباحث وجـود مشـكلات التعبير لدى الطلاب الإندونيسيين في الكلام بشكل عام وفى الكتابة بشكل خاص. فهذا الضعف في الأداء التعبيري بنوعياء الشفهي والكتابي مما يؤثر على قصور فعالية عملية الاتصال داخل الصف

$$
\text { ومستوى التحصيل الدراسي. }
$$

بعـد أن لاحـظ الباحـث مظـاهر المشـكلات في الأداء التعبيـري لـدى الطـلاب الإندونيسـين الدارسين في مختلف الجامعات بالسودان عامة و الدارسين بمعهد الخرطوم الدولي خاصية و ذلك من خلال التعامل و الاتصال اليومي معهم داخل الجامعة و خارجها، يرى أن هناك خصيائص تبين نقطة الضعف في الأداء التعبيري لديهم شفهيا كان أم كتابيا، و من تلك الخصائص: من الجانب الشفهي : n

ا. كثيرا مـن الطلاب الإندونيسـيين يواجهـون الصـعوبات في تنظيم الجمل و مـن ثم تركيـب الأسلوب ليلقيها إلى المستمع رغم أن لديهم قدرا كافيا من المفردات. 
r. معظم الطلبة عند حـديثهم يقعون في الدمج بين الفصحى و العامية ممـا يجعل أسلوب

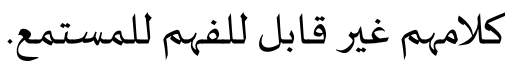

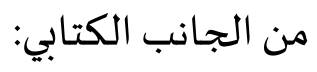

1. لا يستطيع بعض الطلاب الإندونيسيين الذين يعانون من صعوبات في التعبير الكتابي

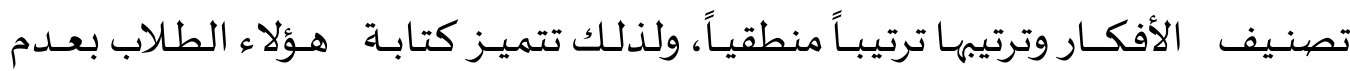
التنظيم والترتيب.

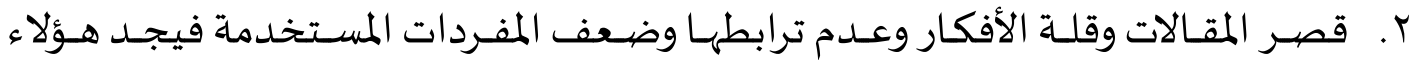
التلاميذ صعوبة في التخطيط للكتابة وتحديد الأفكار الرئيسية والمساندة. انطلاقا من هذا وجد الباحث أن معظم الطلاب الإندونيسيين الدارسين بالسودان لـديهم

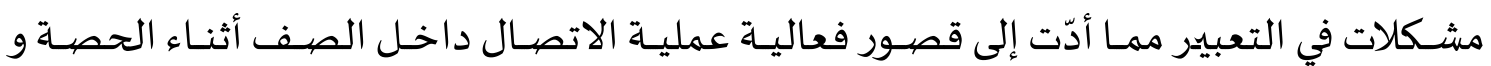
خارجها و ضعف التحصيل الدراسى خاصة.

ويهـدف هـذا البحثث إلى : (1) معرفـة مشـكلات التعبير لـدى الطلاب الإندونيسـيين، (؟) تحديد الأسباب التى تؤدى إلى مشكلات التعبير، (T) معرقة أثر تلك المشكلات في المواقف التعليمية.

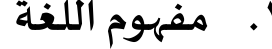

اختلف العلمـاء على تعريـف اللغـة و مفهومها و لـم يكن هنـاك اتفـاق شـامل على مفهوم

محدد للغة. و يرجع سبب الخلاف بينهم إلى أن كلا منهم ينطلق من خلفية علمية خاصة بهاه و كون اللغة نفسها مرتبطة بكثير من العلوم.

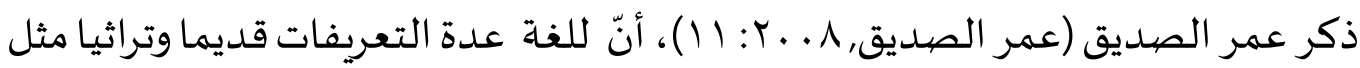

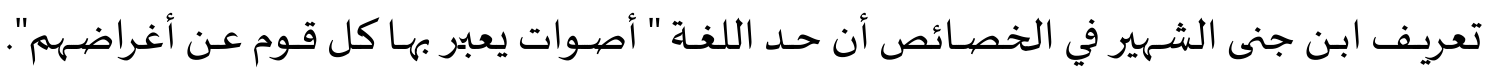
فاللغة ظاهرة إنسانية وغير غريزية لتوصيل العواطف والأفكار والرغبات بواسطة نظام من الرموز

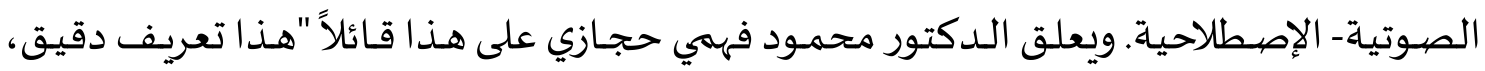

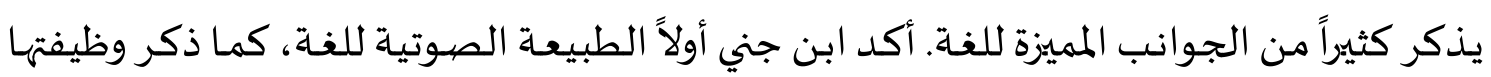

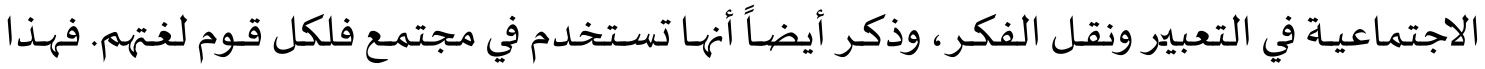


التعريف يتفق مـع عناصـر تعريف اللغـة عند البـاحثين المحـدثين فيمـا تؤكد كل هـذه التعريفـات

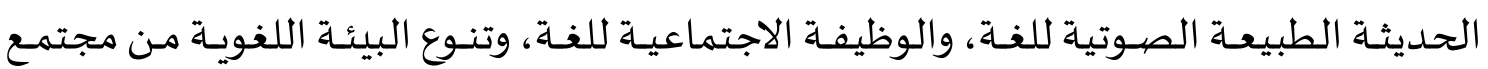
إنساني لآخر "(الطاهر, 11 . ب: 11).

و قـال ابـن خلـدون في تعريف اللغـة "اعلـم أن اللغــة في المتعــارف، هي عبـارة المـتكلم عـن

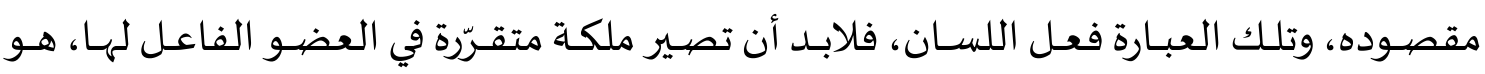

$$
\text { اللسان، وهو في كل أمة بحسب اصطلاحاتهم". }
$$

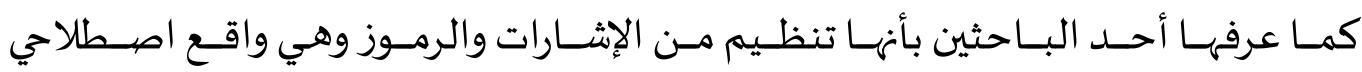

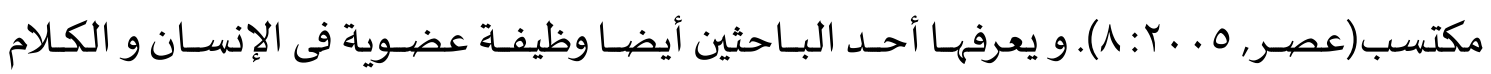

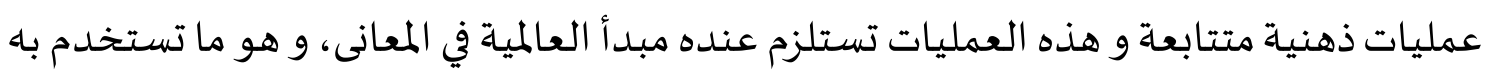
اللغة أداة للتواصل بين الناس(محمد, V. . Y : 10).

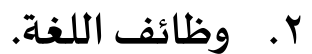

اختلف العلماء و تباينت آراؤهم فيما يتعلق بوظيفة اللغة و الأغراض التى تؤديها. ومن تلك

الوظائف يمكن أن نجملها في الآتي:

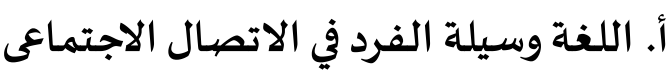

للغة من الناحية الاجتماعية أداة اتصال بين الفردوالفرد، و بين الأفرادو المجتمع، فعن طريقها يتصل الفرد بغيره مشافهة كما يتصل بها كتابيا بالرسالة أو بالبريد الالكترونيك أو نحوهما.

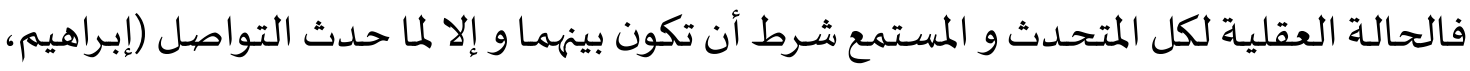

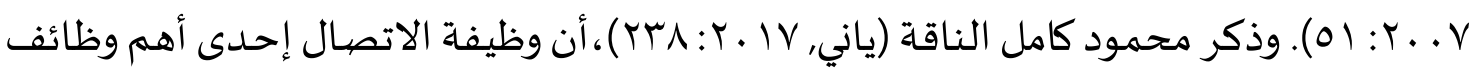

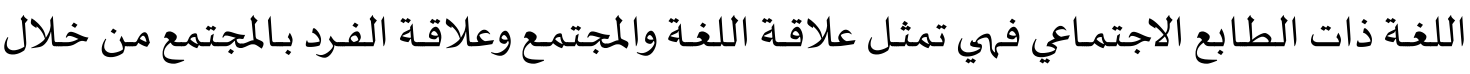

ب. اللغة وسيلة للتقدم الحضباري و الحفاظ على التراث البشري.

اللغة من هذه الناحية هي الوسيلة الأساسية لتسجيل ما أنتجه العقل الإنساني، و علهيا

اعتمدت البشرية في الحفاظ على تراثها.و برموز اللغة الكتابية سجلت حياتها وما حفلت بهاء من 
ثقافـة و علم و فن. و لـولا اللغـة وعـاء التراث و الثقافـة لانقطع المرء في حاضـره عن ماضـيه، و في

$$
\text { ج. مستقبله عن حاضره. }
$$

التعبيز هـو أهم فـرع في اللغـة العبريـة فهو غايـة بينهـا جميعـا. والتعبيز إحـدى الخصـائص

لتعليم اللغــة العربيـة بمهاراتها الأربعـة، هي مهارة القـراءة، ومهارة الكتابـة، ومهـارة الكلام، ومهـارة الاستماع(Al-Amin \& Erwin Syaputra, 2016:345) فإذا كانت المطالعة تزود القارئ بالمادة اللغويـة والثقافـة، وإذا كانت القواعـد النحويـة وسـيلة لصـون اللسـان والقلم عن الخطأ، وإذا كان الإملاء وسيلة لرسـم الكلمات والحروف رسـما صدحيحا فإن التعبير غاية هذه الفروع مجتمعـة وهو غاية تحقيق هذه الوسائل.

و ينبخي التفريق بين مصـطلحى الإنشـاء والتعبييز، وبعض المـبين يميلـون إلى اسـتعمال مصطلح الإنشاء ويؤثرونه على مصطلح التعبير. و الواقع أن كلمة الإنشاء تعني الخلق و الإبداع، و الخلق و الإبـداع ليس مما يتهيـأ لأي إنسـان، و إنمـا أمـر يحتـاج إلى ما يسـّى بالموهبـة أو الاسـتعداد

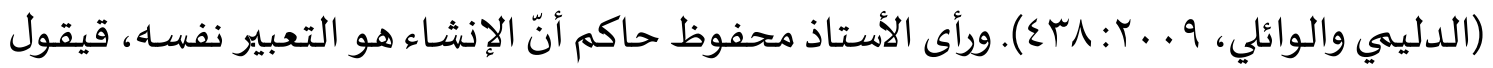
إنّ الإنشاء هو التعبير بالألفاظ نطقا وكتابة عما في نفس من الأغراض والمعاني Masqon, Yoke) Suryadarma, \& Achmad Farouq Abdullah, 2017:146)

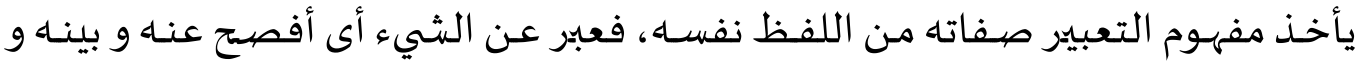
وضـحهاه و يكون هـذا التبيـان أو الإيضـاح بـاللفظ أو بالإشـارة أو بتعبييرات الوجـهـ و الحركة بأنواعها التمثيلية و الواقعية.و لكن مفهوم التعبير في ضوء طرق التدريس هو " الإفصاح عما في النفس من أفكار و مشـاعر بإحدى الطرق السـابقة و خصوصيا باللفظ أو المحادثة و الكتابة (إسماعيل, V . . ؟

و يمكن القـول في تعريـف التعبير بأنـا امتلاك القـدرة على نقل الفكرة أو الإحسـاس الذي يخطر في الذهن أو الصدر إلى السامع و قد يتم ذلك شفويا أو كتابيا على وفق مقتضيات الحال. د. أنواع التعبير.

للتعبير أقسـامه التى يتميز كل منها بما يرتكز عليها مـن أسس و ما يصـطنع من وسـائل أو يرتبط باه من دوافع (إسماعيل, V . . Y: 1 ـ Y)، و ذلك على النحو التالى:

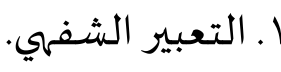


و الوسـيلة هي الكلمـة المنطوقة التى تتحـرك بها الشـفة و إليها نسـب فقيـل " الشـفهي "، و أمثلتـه متعـددة، منهـا : المحادثــة، والمناقشـة، والحـديث الهـاتفي، والأســئلة و الأجوبـة مـن المعلـم أو التلاميذ خلال الدرس، وتلخيص الأفكار و شرحهاو التعليق عليها، وإلقاء الأخبار. و لهذ النوع من التعبير قيمتـه في الحياة التعليمية وفي الحياة بصـورة عامـة. فهو في مرحلة الطفولة عمـاد الثزروة اللغويـة التى تمهـد لتعلم القراءة، و هو قـوام التعبير الحر للطفل، و وسيلة الاتصـال الغالبـة بـين المتحــدث و السـامع، والنـاس يمارسـوناه بصـورة أوسـع ممـا يمارسـون التعبيير الكتـابي. فالإنسـان يـتكلم مـع الأصـــقاء ويبيـع ويشـتري، ويتحـدّثون عـن الأحسداث وغيرهـا بوسـبلة

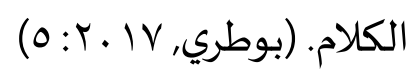

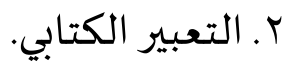
الوسـيلة المسـتعملة فيـه هي الكلمـة المكتوبـة أو المحررة و من أجلها سـميت " الكتابي " أو "

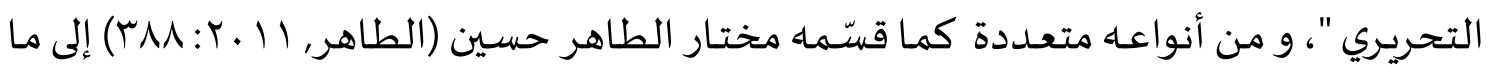

يقـدم المـدرس للطلاب عـددا مـن الأسـئلة تـدور حـول صـورة، أو فقـرة، وتـؤدي الإجـابـة عـن تلك الأسئلة إلى كتاباة عدد من الجمل.

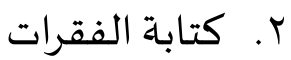

في هذا التـريب يبدأ الطلاب الفقرة بجملة معيّنة، ثمّ يضيفون إليها عددا آخر من الجمل، ويؤدّي ذلك إلى كتابة فقرة كاملة ذات فكرة رئيسية واحدة. r. إعادة كتابة القصية يقرأ المدرّس قصـة بصـوت جهري مرتين أو ثلاث مرّات، ويقوم الطلاب بكتابـة كل ما يمكن تـذكره من القصية.

و يتميز هذا النوع من التعبير بالوضيوح و الدقة و الترتيب و الجمال على المستوى الملائم، و تعني التربية اللغوية في المرحلتي المتوسطة و الثانوية بتنمية مهارته و قدراته لعلوّ منزلته في إنتاج الآثار الأدبية الجميلة. 
للوصيول إلى النتائج المطلوبة والأهداف المنشودة من هذا البحث، استخدم الباحث المنهج الوصفي حيث قام بتحليل مشكلات التعبير التى يعانى منها الطلاب الإندونيسيون الدارسون بمعهد الخرطوم الدولى وذلك من خلال استخدام الاستبانة للدارسين تختصّ بجوانب المشكلة المختلفة فى التعبير.

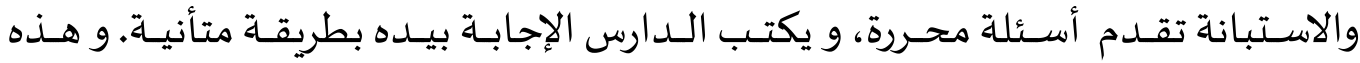
الاســبانة تنقســم إلى مجمـوعتين, المجموعــة الأولى تتعلـق بالمعلومــات الأسـاسـية التي تتعلـق بالمفحوصين وهي تحتوي على أربع نقاط، و المجموعة الثانية تشتمل على أربعة محاور، بينما المحور الأول يحتوى على ستة أسئلة و بقية المحاور تحتوى على ـr عبارة. وهي عبارة عن فروض الاستبانة, المحور الأول يتعلق بالخلفيات التعليمية للغة العربية, و المحور الثانى يتعلق بمشكلات التعبير التى يعانى منها الطلاب,و المحـور الثالث يتعلق بالعوامل المؤثرة فى مشـكلات التعبير لـدى الطلاب,و المحور الرابع يتعلق بأثر الضعف التعبيري في الدراسة. يتكون مجتمع الدراسـة من الطلبة الإندونيسيين الدارسين في معهد الخرطوم الدولى للغـة العربيـة بمحتلف مـراحلهم ومسـتوياتهم. اختـار الباحث من هـذا المجتمـع عشـين طالبـاو طالبـة كعينة للدراسة التحليلية و هم يجلسون في مختلف المراحل و المستويات. بعـد مـا أتم الباحثث تصـميم هـذه الاسـتبانة في المـرة الأولى، قـام بعرضهها على المحكمـين ليستنير بتوجيهاتهم وإرشـاداتهم، في مـدى ارتبـاط مفـردات الاسـتبانة بالأهــاف التي صـممت مـن أجلها، ومدى وضيوح اللغة ومناسبتها للعينة المستهدفة. إضـافة إلى وضوح تعليمات وصصحة ترتيب الخطوات الأسساسية. ومن ثم اطمئن الباحث من خلال دراسته الحالية بأن هذه الأداة تتوفر فيها درجة عالية من الثبات والصدق. بعـد جمـع المعلومات من المفحوصين، قـام الباحث بتفريخ الاسـبانة ومعالجـة المعلومات بالطريقة الإحصائية واتبع الباحث الخطوات التالية: 1. تم حصر وإحصاء التكرار أو العدد في كل خيار من خيارات الأسئلة في كل قسم من أقسـام

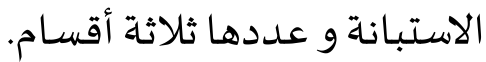


r. اسـتخرج الباحـث النسـبـة المئويـة لكـل خيـار مـن الخيـارات عـن طريـق النســبة المئويــة

لاستجابة.

يفسر الباحث عبارة " إلى حد ما" في الاستبانة على أهها رأي ما بين الموافقة وغير الموافقة ثم يرى الباحث أن هذا الرأي عبارة عن التردد في نفوس العينات لكنه أقرب ما يكون إلى الموافقة من عدم الموافقة وذلك لأن العبارات المصيوغة في الاستبانة خالية من أداة النفي.

\section{بحث ومناقشـة}

$$
\text { ا ـ العوامل المؤثرة في مشكلات التعبير لدى الطلاب الإندونيسيين. }
$$

أكـدت الدراســات على اختلافهـا أن ضـــف التلاميـذ والطلبــة فى التعبيـر بـل إن بعـض الدراسـات أثبتت قصهورا شـديدا في التعبير لدى المتعلمين فى المراحل الدراسية كافة(الدليمى \& د.

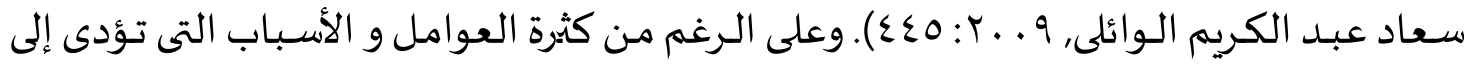
الضعف البين في التعبير فيريد الباحث أن يأخذ هذه الأسباب إلى محورين أسـاسين:

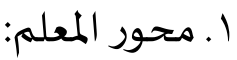

إن قسـما من المتعلمـين يتحـدثون أمـام طلبتهم باللهجــة العاميـة، ولا يخفى مـا للعاميـة من أثر سـئ في اكتسـاب الطالب للغـة، لأن الطالب يقتـــى بمعلميـاه و يحـاكيهم و يـتعلم منــا الكثير حينما يتحـدث ويشـرح و يوجـاه، ومن هنـا كان من الضـرورى أن تكون لغـة المعلمين و المتعلميـن في الصف سـليمة فصيحة. وهنـا ينبخى أن يكون الحـديث باللغـة العربيـة الفصيـحة التى هى أقصىى آمال الطالاب الإندونيسيين عندما جـاءوا إلى السـودان متمنيين إيجـاد البيئة العربية الحقيقية فى الموقف الدراسي، فلما انعكس الحال عما يتمنونها فبعضههم يفتقدون الحماسـة والرغبـة في تعلم اللغة العربية على وجاه الخصوص.

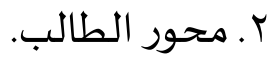
وأما من ناحية الطالب تتبين العوامل التالية : 
ا. شـيوع اسـتخدام اللهجـات العاميـة إلى الحـد الذى جعلها تضـايق الفصيح، فالعاميـة لغـة التواصـل في البيت والمجتمع وسـاحة المدرسـة، وتكون سـاعة الطالب خـارج غرفـة الصـف أكثر مما يجلسون فيها، فهذا مما يجعلهم يمارسون العامية أكثر من الفصحى. r. تـأثر اللهجــات القوميـة الإندونيسـية ممـا يجعلهـم يصـعبون في تكـوين اللهجــة العربيـة الفصحى وذلك لاختلاف الجانب الصوتى بين اللغة الإندونيسية واللغة العربية. r. انصـراف الطلبـة من ميـادين النشـاط اللغوى مثـالا الصححافة والخطابة والمنـاظرات والندوات خارج الجامعة. ع. قـلة التـدربب في كتابـة الموضـوعات العربية فالطلبـة لا يعتادون في تنظيم الأفكار وترتيبها فيجدون صيعوبة عندما يبدأون كتابة الفقرة التى تتطلب فيها الترابط والتسلسل المنطقي

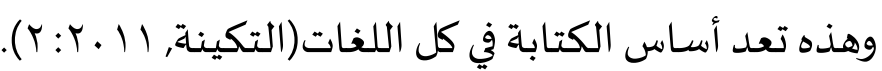
0. الطريقة التى تعلم بها الطلاب الإندونيسيين اللغـة العربية في مدرستهم بإندونيسيا لها أثر فعال فى تجويــ بعض جوانب اللغـة و إهمال الجانب الآخر و ذلك مما لمسـه الباحث من

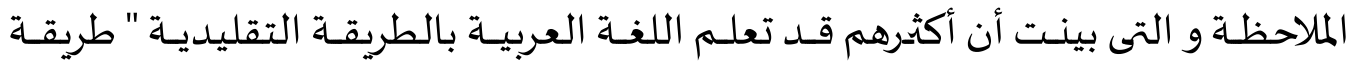
القواعـد والترجمــة " التى تركز على حفـظ القواعـد ممـا أثر في إجـادة الدارسـين للقواعـد والقراءة وضعفهم في الجانب التطبيقي خاصهة مهارة الكلام والإنشاء.

بعـد اسـتخراج نتـائج الاسـتبانة حـاول الباحث الكشـف عـن تلك المشـكلات و التعرف على أسبابها و من ثم الوصول إلى معرفة ما أثر تلك المشكلات في الدراسـة. أ. مشكلات التعبير التى يعانى منها الطلاب الإندونيسيون القسم الأول : من ناحية الأداء الشفهي يمكن ترتيب مشكلات التعبير التى يعانى منها الطلاب الإندونيسيون في الأداء الشفهي حسب درجـة نسبتها كالآتي :

ا ـ الوقوع في الدمج بين الفصحى و العامية عند المحادثة. حصلت هـذه العبـارة على الرتبـة الأولى من مشـكلات التعبير التى يعـانى منها الطلاب. يرى الباحث أن سـبب ذلك أن الطلاب يمارسـون العاميـة أكثرِ من الفصـحى ممـا يجعلهم غير معتـادين 
على المحادثة دون اختلاط العامية فيها. فهذا يعكس تماما بحال الطلاب الإندونيسيين قبل تعرفهم بالعاميـة و ذلك فى أول فترة مجيئهم إلى السـودان إذ لم يعرفـوا ولو كلمـة مـن العاميـة، فيتحـدثون الفصحى بمن يلزم مخاطبته بالعربية، فلا يخطر فى أذهانهم شيء من العامية فلا يقعون فى الدمج

r. الصعوبة في استخدام اللغة الفصدح في المحادثة و الحوار. حصلت هـذه العبارة على الرتبـة الثانيـة، و يرى الباحث أن السبب في ذلك يرجع إلى البيئة التى تعامل فيها الطلاب خارج الجامعة. لاحظ الباحث أن هناك اختلافا تاما في القدرة على التحدث بالفصـحى بين الطلاب الإندونيسـيين الذين سـكنوا خـارج الداخليـة والـذين سـكنوا فى الداخليـة و اختلطوا بالطلاب من مختلف الدول حيث أههم يمارسون الفصحى و اعتادوا في استخدامها.و يرى

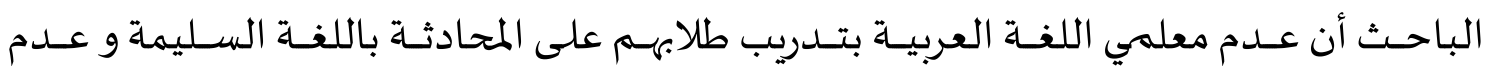
تشجيعهم على الاكثار من التحدث باللغة الفصيحة يكون سببا في هذه المشكلة.

\section{r. الصعوبة في تنظيم الجمل و تركيب الأسلوب عند إلقاء الكلمات.} حصلت هذه العبارة على الرتبة الثالثة، يرى الباحث يمكن القول في سبب ذلك أن الطريقة التى تعلم بها الطلاب الإندونيسيون اللغـة العربية فى مدراسهم بإندونيسيـا لها أثر فعال فى تجويـ بعض جوانب اللغـة و إهمال الجوانب الأخـرى، كمـا أشـار ت نتيجــة الاستبانة أن . ^\% من طلاب العينـة يوافقـون على ذلك السبب ممـا لها أثر في تحسـين مسـتوى جوانب اللغـة المختلفـة و إهمال الجوانب الأخرى، فالطلاب الذين تعلموا اللغـة العربية بالطريقة التقليدية لا يعتادون على الكلام فيتصبعبون فى تنظيم الجمل و تركيب الأسلوب فى المحادثة.

القسم الثاني : من ناحية الأداء الكتابي

يمكن ترتيب مشكلات التعبير التى يعانى منها الطلاب اللإندونيسيين في الأداء الكتابي حسب درجـة نسبتها كالآتي : ا ـ قلة المحصيول اللغوي من المفردات تشكل صعوبة في بناء الجملة.

Please cite this article as Mochammad Firdaus. (2019). Problems in Expressing Arabic Language of Indonesian Students at Khartoum International Institute for Arabic Language. Izdihār : Journal of Arabic Language Teaching, Linguistics, and Literature, 2(1), 35-52. DOI: 
حصيلت هـذه المشـكلة على الرتبـة الأولى من بين مشـكلات التعبيير التى يعـاني منهـا الطلاب الإندونيسـيون في الأداء الكتـابي. لاحظظ الباحث أن كثيرا مـن الطلاب الذين يعـانون مـن صـوبات كتابية لا يملكون العدد الكافي من المفردات اللازمة للتعبير التحريري.و من الملاحظ أيضيا أن كثيرا من الطلاب الذين يعـانون مـن صعوبات في التعلم لا يملكون إلا قلـيلا مـن المفردات بسـبب نقـص الخبرات لديهم، و يرى الباحث أن السبب المؤدي إلى ذلك هو قلة القراءة من نفس الطالب و عـدم تنوع المادة المقروءة حيث أن الصلة وثيقة بين القراءة و التعبير ، و التعبير لا يجود إلا بكثرة القراءة.

\section{r. الصعوبة في تنظيم و تصنيف الأفكاربشكل منطقي في الكتابة.} حصـلت هـذه المشـكلة على الرتبـة الثانيـة. لاحظظ الباحث أن كثيرا مـن الطلاب يواجهـون الصيعوبات فى تصـنيف الأفكار و ترتيبها ترتيبـا منطقيـا، و لـذلك تتميز كتـابتهم بعـدم التنظيم و الترتيـ، و توجــ كثيرا الفكرة الواحـدة موزعـة في عـدة جمل و فقـرات. بعـد الملاحظة العميقـة من خلال البيئة المحيطة بـالطلاب الإندونيسـيين يـرى الباحث أن السـبب لهـذه المشكلة يرجـع إلى نـوع الطريقـة التى تعلـم بها الطلاب الإندونيسـيون في بلادهـم. فـالطلاب الـذين تعلمـوا اللغــة العربيـة بالطريقة التقليدية و التوليفية أكثر ممن تعلموا بالطريقة المباشـرة، إذ كل من الطريقة التقليدية والتوليفة لا تجعل الطلاب يعتادون على تصنيف الأفكار ودور المتعلم فيها محصيور والدور الأكبير يقوم عليه المعلم، و هذا بخلاف الطريقة المباشرة إذ تجعل المتعلم يركز على ما يرى و يسمع أماماه، فتنظيم الأفكار و تصنيفها أصبحت موصلة إلى الفهم، فدور المتعلم فيها أكبر من المعلم.

\section{r. الصعوبة في نقل المعلومات في إجابة أسئلة الامتحان المقالي.} حصيلت هـذه المشـكلة على الرتبـة الثالثـة، لاحـظ البـاحث أن كثيِرا مـن الطلاب يواجهـون الصعوبة فى استرجاع ما قد قرأواو نقلها على أوراق الامتحان، و يصعب عليهم تطبيق قواعد اللغنة لذلك كانت كتابتهم تقع فى الأخطاء النحوية و الإملائية التى تغير المعنى فى كثير من الأحيان، فهذا ما يؤثر فى تحصيلههم الدراسي لعدم فهم المصححين بكتابة الطلاب عند تصحيح أوراق امتحانهم. يرى الباحث أن السبب في ذلك يرجـع إلى أن اعتمـاد الطلاب على الملخصـات و الحفظظ عنـد الاستعداد لمقابلة الامتحان يجعلهم غير معتادين على تنظيم و تصنيف الأفكار.و يتفق هذا السبب مع نتيجـة الاستبانة المبينة بأن معظم الطلاب يفضلون الامتحان الموضوعي و بلغت نسبتهم ه٪\% من العينة. 
ب. العوامل المؤثرة في مشكلات التعبير لدى الطلاب

يمكن ترتيب العوامل المؤثرة في مشكلات التعبير لدى الطلاب حسب درجاة نسبتها كالآتي:

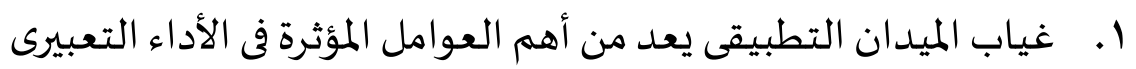

الجدول ا ـ العوامل المؤثرة في مشكلات التعبيرلدى الطلاب

\begin{tabular}{|c|c|c|c|c|}
\hline المجمموع & لا أو افق & إلى حد ما & أو افق & \\
\hline$r$. & - & $r$ & 11 & العدد \\
\hline$\% 1 \ldots$ & - & $\% 1$. & $\% q$. & النسبـة \\
\hline
\end{tabular}

يتضيح من هـذا الجـدول ا أن ـ 9\% من الطلاب يوافقون على أن غيـاب الميدان التطبيقى

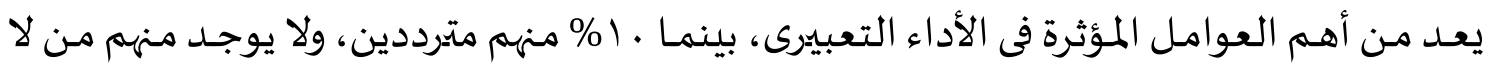
يوافق على ذلك.

r. الطريقة التى تعلم بها الطلاب الإندونيسيون اللغـة العبيـة في مدراسهم بإندونيسيا لها أثر فعال في تجويد بعض جوانب اللغة و إهمال الجوانب الأخرى

الجدول ץ. آراء الطلاب حول الطريقة التي تعلم بها الطلاب في مدارسهم بإندونيسيا

\begin{tabular}{|c|c|c|c|c|}
\hline المجمموع & لا أو افق & إلى حد ما & أو افق & \\
\hline r. & - & $\varepsilon$ & 17 & العدد \\
\hline$\% 1 \ldots$ & - & $\%$ r. & $\% \wedge$. & النسبة \\
\hline
\end{tabular}

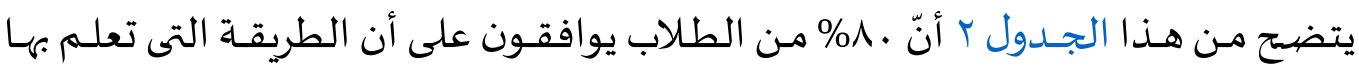

الطلاب الإندونيسيون اللغة العربية في مدراسهم بإندونيسيا لها أثر فعال في تجويد بعض جوانب اللغة و إهمال الجوانب الأخرى، و • † منهم مترددين، ولا يوجد منهم من لا يوافق على ذلك. 
r. استخدام المعلم اللهجات العامية في الصف يجعل الطالب يفتقد الرغبة في مشـاركة الدرس.

الجدول س. آراء الطلاب عن استخدام المعلم اللهجات العامية في الصفف

\begin{tabular}{|c|c|c|c|c|}
\hline المجمموع & لا أو افق & إلى حد ما & أو افق & \\
\hline r. & $r$ & $r$ & 10 & العـدد \\
\hline$\% 1 \ldots$ & $\% 1$. & $\% 10$ & $\%$ \% & النسببة \\
\hline
\end{tabular}

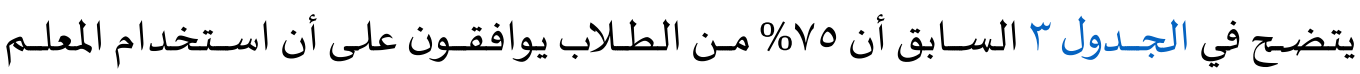

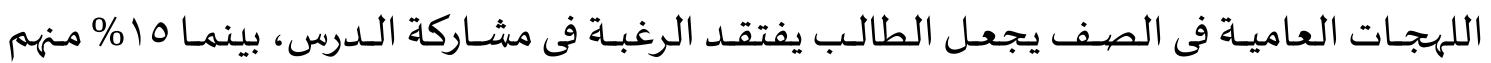
مترددين، وأن • ا \% منهم لا يوافقون على ذلك. ج. أثر الضعف التعبيري فى الدراسـة يمكن ترتيب أثر الضعف التعبيري في الدراسة حسب درجة ذسبتها كالآتي: 1. ضعف الطلاب فى التعبير يؤثر سلبا فى تحصيلهه الدراسى بصفة عامة. الجدول ع. آراء الطلاب عن أثر الضعف في التعبير

\begin{tabular}{|c|c|c|c|c|}
\hline المجموع & لا أو افق & إلى حد ما & أو افق & \\
\hline r. & $r$ & 0 & Ir & العـدد \\
\hline$\% 1 \ldots$ & $\% 10$ & \%ro & $\% 7$. & النسببة \\
\hline
\end{tabular}

يتضح من هذا الجـدول \& أن . 7\% من الطلاب يوافقون على أن ضعف الطلاب في التعبير يؤثر سلبا فى تحصيلههم الدراسى بصـفة عامـة، وأن 0\% \% منهم أيضيا مترددين، و 0 \% \% منهم لا يوافقـون على ذلك.

r. الضـعف فى الأداء التعبيـرى يـؤدى إلى نفــور الطالب مـن المشـاركة فى منـاقشـة الـدرس أثنـاء الحصة لعدم القدرة على نقل الأفكار عما خطر فى ذهنه. 
الجدول ه. آراء الطلاب عن أثر الضعف في الأداء التعبيري

\begin{tabular}{|c|c|c|c|c|}
\hline المجموع & لا أو افق & إلى حد ما & أو افق & \\
\hline r. & 0 & V & $\Lambda$ & العـدد \\
\hline$\% 1 \ldots$ & $\%$ ro & $\%$ ro & $\% \varepsilon$. & النسببة \\
\hline
\end{tabular}

يتضح من هذا الجدول 0 أن • ع\% من الطلاب يوافقون على أن الضعف فى الأداء التعبيرى يؤدى إلى نفور الطالب من المشـاركة فى مناقشـة الدرس أثناء الحصية لعدم القدرة على نقل الأفكار عما خطر فى ذهنه، و هب\%\% منهم مترددين، كما لا يوافق 0ب\% منهم على ذلك.

بعد مناقشة هذه المشكلات التى يواجهها الطلاب الإندونيسيون بجميع أسبابها، يرى الباحث أن العامل الأكبر المؤثر في هذه المشكلات هي غياب الميدان التطبيقي وانصراف الطلاب الإندونيسين من ميادين النشاط اللغوى، كالندوات اللغوية والمحاضرات العامة داخل الجامعة أو خارجها, و ذلك أن معظم الطلاب يرون أن غياب الميدان التطبيقي يكون أهم العوامل المؤثرة في ضعف التعبير الذى يمكنهم من خلاله تطوير مهارتهم اللغوياة شفهية كانت أم كتابيا، و . 0\% منهم يرون أن السبب فى ذلك يرجع إلى إنصرافهم من ميادين النشاط اللغوي، فهذا مما يجعل الطلاب الإندونيسين ليس لهم مجال لتدريب و تطوير مهارتهم في التعبير شفهيا وكتابيا. فيؤثر ذلك الضعف التعبيري إلى ضعف التحصيل الدراسي لديهم و ذلك أن ـ 7\% من الطلاب يوافقون على أن ضعفهم في التعبير يؤثر سلبا فى تحصيلهم الدراسي. فيرى الباحث أن هناك علاقة وتيدة بين ضعف الطلاب في التعبير و تحصيلهم الدراسي، و يؤكد ذلك أن ـع\% من الطلاب يرون أثر ضعفهم في التعبير فى عملية التعليم و التعلم، وذلك عدم مشاركتهم في مناقشة الدرس أثناء الحصية والخوف من الاستفسار عما لم يفهموه من الدرس، فهذا مما أدى إلى ضعف مستوى فهمههم للمادة التى يشكل صعوبة لههم فى إجابة أسئلة الامتحان، فيكون أثرا في مستوى تحصيلهم الدراسي فيما بعد. 
أ. إن كثيررا مـن الطلاب الـذين يعـانون الصـعوبات في التعبيهر يتصـبون في تنظيم الجمل و تركيـب الأسـلوب في المحادثـة و الكتابـة، و هـم أيضـا يجــدون الصـعوبة في تصـنيف الأفكار و ترتيبها ترتيبا منطقيا في الكتابة، و لذلك تتميز كتابتهم بعدم التنظيم و الترتيب، و توجد كثيرا الفكرة الواحدة موزعة في عدة جمل و فقرات. ب. إن ضعف الطلاب الإندونيسيين في التعبير يرجع إلى أسباب أهمها: ا. الطريقة التى تعلم بها الطلاب الإندونيسيون اللغة العربية في مدراسهم بإندونيسيا لها أثر فعال في تجويد بعض جوانب اللغة و إهمال الجوانب الأخرى. فالطلاب الذين تعلموا اللغة العربيـة بالطريقـة التقليديـة يركزون عالى حفـظ القواعـد ممــا يـؤثر فى إجـادة الدارســـن للقواعد و القراءة و ضعفهم في الجانب التطبيقي خاصة مهارة الكلام و الإنشاء.

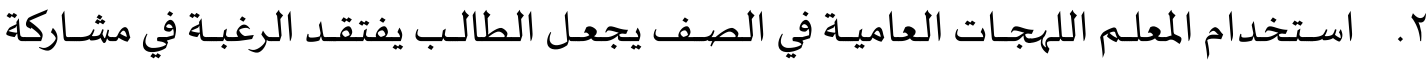
الدرس، فلها أثر سيئ في اكتسـاب الطالب للغـة، لأن الطالب يقتـدى بمعلميـه و يحاكيـه و يتعلم منهم الكثير حينما يتحدث و يشرح و يوجاه. r. إن عـدم إتاحـة المعلم الفرص للطلاب في النقاش و الاستفسـار عن الدرس يجعل الطالب سلبيا أثناء الحصية و غير متفاعل. ع. أثر اللهجـات القوميـة الإندونيسية يجعل الطلاب يجـدون صعوبة في تكوين اللغـة العربية الفصحى و ذلك لاختلاف المستوى الصوتى بين اللغة الإندونيسية و اللغة العربية. 0. ممارستهم للعامية أكثر من الفصحى نتيجة عن تعاملهم مع المجتمع السوداني، و من خلال

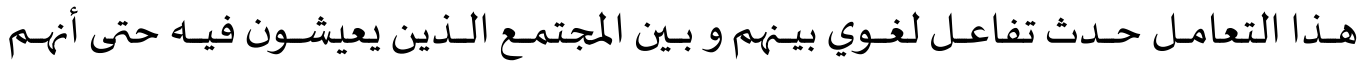
يمارسون العامية و كادوا يتركون الفصحى. 7. ضعف ثقافتهم التى لا تشجعهم على المحادثة الشفهية. V. غيـاب الميـدان التطبيقي لتنميـة مهارة لغويـة لـدى الطلاب شـفاهة و كتابـة يعـد مـن أهـم العوامل المؤثرة في ضعفههم في التعبير. ج. إن مشكلات التعبير التى تواجه الطلاب لها أثرفي المو اقف التعليمية، منها : ا. الضعف في التعبير يجعل الطالب غير متفاعل أثنـاء الحصية و ذلك لعـدم قـدرهم على نقل الأفكار لمناقشة الدرس. 
r. إن معظم الطلاب الإندونيسـين الدارسـين بمعهـد الخرطوم الـدولى للغـة العربيـة يفضيلون الامتحان الموضوعي حيث لا يتطلب منهم انتقاء الأفكار و ربطهاو تنظيمها و من ثم كتابتها

$$
\text { على الفقرات. }
$$

r. عند الاستعداد للامتحان يميل الطلاب إلى الاعتماد على الملخصات و الحفظ.

إن ضعف الطلاب في التعبير و رغبتهم عن الامتحان المقالي و اعتمادهم على الحفظ و الملخصات عند مواجهة الامتحان يؤدي إلى ضعف التحصيل الدراسي لديهم، وذلك لصعوبة نقل المعلومات و انتقاء الأفكار، حيث أن حفظ المقررات أو المذكّرة لا يعوّدهم على تنظيم الأفكار و تركيها بأسلوبهم، فعندما جاء الامتحان على الشكل المقالي و يطلب منهم إبداء رأيهم فيجدون صعوبة في استرجاع ما قد قرأواو نقلها على أوراق الامتحان.

Al-Amin, N. S., \& Erwin Syaputra. (2016). Kemampuan Pengurus Rayon dalam Ta'bir Tahriri di Pondok Modern Darussalam Gontor. At-Ta'dib, 11(2).

Masqon, D., Yoke Suryadarma, \& Achmad Farouq Abdullah. (2017). Analisis Problematika Pembelajaran Insya' Insya' Tahriri Santri Kelas V (KMI) di Pondok Modern Gontor Dua. AtTa'dib, 12(2).

: دار الفكر. إسماعيل, ز. (V . . r ). طرائق تدردس اللغة العربية أبو الضبعات.

: مطبعة جامعة النيلين. التكينة, إ. (1 ( ـ ( ). مدخل إلى كتابة الفقرة.

$$
\begin{aligned}
& \text { الدليمى, ط. ع. ح.، \& د. سعاد عبد الكريهم الوائلى. (9 . . ؟). اتجاهات حسديثة فى تدريس اللغة }
\end{aligned}
$$

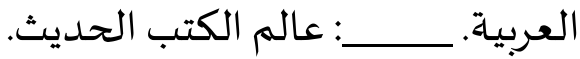

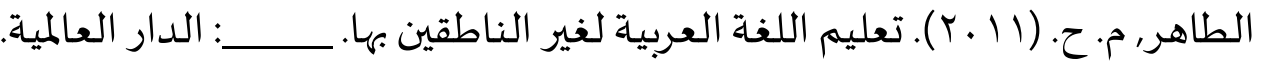

بوطري, أ. (V V . r). تطوير استراتيـجية تعليم مهارة الكام من خلال مدخل .NLP مجلة لسـانيات,

) $.1(\wedge$

(مركز الاسكندرية للكتاب. No Title.

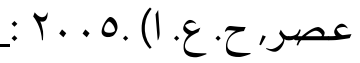

Please cite this article as Mochammad Firdaus. (2019). Problems in Expressing Arabic Language of Indonesian Students at Khartoum International Institute for Arabic Language. Izdihār : Journal of Arabic Language Teaching, Linguistics, and Literature, 2(1), 35-52. DOI: 


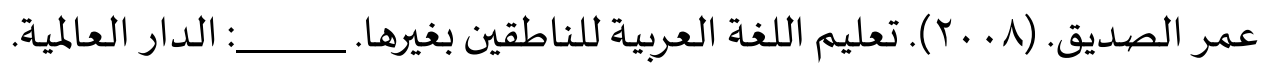

مؤسسة حورس محمد, ص. م. إ. (V . . r). مهارات التفكير و تعلم اللغة العربية و تعليمها.

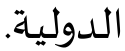

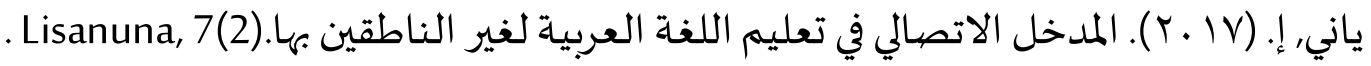

